Check for updates

Cite this: Phys. Chem. Chem. Phys., 2020, 22, 966

Received 5th November 2019 Accepted 6th December 2019

DOI: $10.1039 / c 9 c p 06017 k$

rsc.li/pccp

\section{Is basicity the sole criterion for attaining high carbon dioxide capture in deep-eutectic solvents? $\dagger$}

\author{
Shashi Kant Shukla, (D) *a Dariush Nikjoo ${ }^{\mathrm{b}}$ and Jyri-Pekka Mikkola*ac
}

\begin{abstract}
A critical analysis of the role of Hammett basicity $\left(H_{-}\right)$and aqueous basicity $\left(\mathrm{p} K_{\mathrm{a}}\right)$ in $\mathrm{CO}_{2}$ uptake in deep-eutectic solvents (DESs) suggests that neither $\mathrm{H}_{-}$nor $\mathrm{p} K_{\mathrm{a}}$ correlates with the $\mathrm{CO}_{2} \mathrm{w} / \mathrm{w} \%$ capacity in the studied DESs. Instead, strong "synergistic interactions" between donor and acceptor moieties satisfactorily relate to the $w / w \%$ of $\mathrm{CO}_{2}$ in DESs.
\end{abstract}

The use of renewable energy as the primary energy supply also requires the improvement in the conservation efficiency of fossil fuels and can only be accomplished by efficient environmentfriendly carbon dioxide $\left(\mathrm{CO}_{2}\right)$ capture. ${ }^{1}$ The anthropogenic emissions of $\mathrm{CO}_{2}$ in the atmosphere are surging day-by-day and increasing the threat of global warming. ${ }^{2}$ The current state-ofthe-art technology in the $\mathrm{CO}_{2}$ capture is the use of basic amine solutions as a scrubber though this methodology is associated with several critical shortcomings such as high regeneration energy, amine volatility and corrosivity and high maintenance cost of the setup. ${ }^{3,4}$

The past century has witnessed a lot of effort in quest of "green and sustainable" solvents alternative to volatile organic solvents. Among them, ionic liquids (ILs) and deep-eutectic solvents (DESs) have garnered maximum attention, as they have the potential to be utilized in various applications because of their advantageous properties such as often insignificant vapour pressure, high thermal stability, a wide liquidus range, low flammability and good recyclability. ${ }^{5,6}$ In the past two decades, interest emerged in testing the ability of both ILs and DESs as scrubber solvents in the acid gas $\left(\mathrm{CO}_{2}\right.$ and $\left.\mathrm{SO}_{2}\right)$ sequestration.

\footnotetext{
${ }^{a}$ Technical Chemistry, Department of Chemistry, Chemical-Biological Centre, Umeå University, SE-90187 Umeå, Sweden. E-mail: shashi.kant.shukla@umu.se, jyri-pekka.mikkola@umu.se

${ }^{b}$ Division of Materials Science, Luleå University of Technology, SE-97187, Luleå, Sweden

${ }^{c}$ Industrial Chemistry \& Reaction Engineering, Department of Chemical, Engineering, Johan Gadolin Process Chemistry Centre, Åbo Akademi University, FI-20500 Åbo-Turku, Finland

$\dagger$ Electronic supplementary information (ESI) available: Synthesis and characterization of DESs, experimental methods etc. See DOI: 10.1039/c9cp06017k
}

The pioneering work of Blanchard's et al. showed that $\mathrm{CO}_{2}$ can be partitioned in the IL phase with the least contamination to the $\mathrm{CO}_{2}$ phase. ${ }^{7}$ This study garnered the attention of researchers worldwide and the last decade has witnessed an upsurge in utilizing ILs in the $\mathrm{CO}_{2}$ capture. ${ }^{8-10}$ As an example, use of a $60 \%$ IL-water mixture instead of aqueous monoethanolamine (MEA) lowered the energy costs by $16 \% .{ }^{11}$

Later, significant improvements in the $\mathrm{CO}_{2}$ capture were noticed upon the introduction of a basic moiety on the cation side-chain and involving a highly basic anion. ${ }^{12-23}$ However, a direct correlation of $\mathrm{CO}_{2}$ loading $(\mathrm{w} / \mathrm{w} \%)$ with the basicity is missing for ILs. Despite the extensive research efforts in the $\mathrm{CO}_{2}$ capture in ILs, these coulombic solvents turn into a viscous glue and hence render regeneration very difficult. ${ }^{24,25}$ Furthermore, the synthesis of task-effective ILs is not cost-competitive as it requires several synthetic and purification steps compared to MEA. $^{13,22,26}$

Contrary to the ILs, DESs, which require a single step atomeconomic process and have properties analogous to ILs, provide a promising alternative in $\mathrm{CO}_{2}$ capture and result in a higher gravimetric uptake. ${ }^{27}$ The efficiency of DESs in $\mathrm{CO}_{2}$ capture relies on complexing an adequate hydrogen bond acceptor (HBA) with an efficient hydrogen bond donor at an optimal molar ratio. ${ }^{28}$ Because of the ease in terms of property tunability, in a short span, DESs have found application in synthesis, polymerization, stabilization of biomolecules, nanotechnology, separation, extraction of various compounds and so on. ${ }^{29-33}$ The screening of DESs in $\mathrm{CO}_{2}$ capture showed moderate to high $\mathrm{CO}_{2}$ uptake in potential DESs. ${ }^{34-40}$ Out of several structural features of DESs, the role of HBD components was acknowledged more in attaining high gravimetric $\mathrm{CO}_{2} \cdot{ }^{35-37}$

Despite the huge success in identifying the potential media for $\mathrm{CO}_{2}$ capture, the major discussion revolves around the acidbase interactions between the solvents and $\mathrm{CO}_{2}$ molecules. Be it the aqueous MEA, methyldiethylamine (MDEA), ionic liquids (ILs) or deep-eutectic solvents (DESs), basicity has been the only criterion suggested for the high $\mathrm{CO}_{2}$ uptake although it failed at some instances. ${ }^{40}$ The activation of amino-acid ILs by the 
carboxyl group has shown the importance of the "multiple-site interactions" in multimolar $\mathrm{CO}_{2}$ capture. ${ }^{41}$ Recently, we discussed the significance of the intermolecular interactions in guiding high $\mathrm{CO}_{2}$ uptake in DESs. ${ }^{42}$ The "synergistic interaction" between the donor and acceptor moieties in DESs was observed as the controlling parameter in the temperature-dependent $\mathrm{CO}_{2}$ capture in ethylenediamine (EDA)- and polyamine-based DESs. $^{43}$ Though the multiple-site-, intermolecular- and synergistic-interactions are accounted where basicity does not act as a guiding factor, their applicability, especially the synergistic interactions, which can be represented by making use of the Kamlet-Taft parameters, ${ }^{43}$ has not been tested as a guiding criterion in the acid gas capture. The current work presents a critical discussion about the role of basicity and synergistic interactions in the $\mathrm{CO}_{2}$ uptake in DESs. The Hammett basicity $\left(H_{-}\right)$and aqueous basicity of HBD components are applied as basicity parameters for DESs.

The DESs employed in the present work were synthesized by complexing monoethanolammonium chloride ([MEA.Cl]), tetrabutylammonium bromide ([TBAB]), and diethylenetriammonium trichloride ([DETA.Cl]) with moderate to high basicity HBDs such as ethanolamine ([EA]), diethanolamine ([DEA]), triethanolamine ([TEA]), [EDA], 3-amino-1-propanol ([AP]) and tetraethylenepentamine ([TEPA]) (see the ESI $\dagger$ for synthesis, entry 1) and their structures are exhibited in Fig. 1. Their characterization results and $\mathrm{CO}_{2}$ uptake monitoring by ${ }^{13} \mathrm{C}$ NMR are given in the $\mathrm{ESI} \dagger$ (entries 2-6).

For all the DESs, the $\mathrm{CO}_{2}$ uptake at saturation, Hammett basicity $\left(H_{-}\right)$, pseudo-rate constant $(k)$ and some Kamlet-Taft parameters $(\alpha$ and $\beta$ ) are shown in Table 1 and their methods are discussed in the ESI $\dagger$ (see entry 7$). E_{\mathrm{T}}(30)$ and $\pi^{*}$ are given in Table S2 (see the ESI $\dagger$ ). For all the DES systems, the mass of $\mathrm{CO}_{2}$ captured was observed to fit into an exponential growth model equation proposed by Box \& Lucas (see the ESI, $\dagger$ Fig S34).

$$
w_{\mathrm{CO}_{2}}=a\left(1-\mathrm{e}^{-k t}\right)
$$

where $a$ is the maximum amount of $\mathrm{CO}_{2}$ absorbed in DESs and $k$ is the pseudo-rate constant for the $\mathrm{CO}_{2}$ capture. The parameter $k$ does not represent the first order kinetics by any means

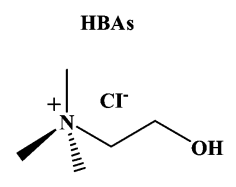

Choline chloride ([ChCl])

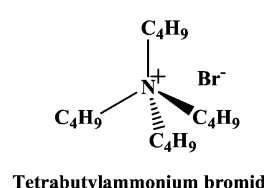

Tetrabutylammonium bromide ([TBAB])

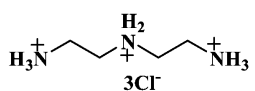

Diethylenetriammonium chloride ([DETA.CI])

Fig. 1 Structure of DESs.
Table 1 Gravimetric $\mathrm{CO}_{2}$ uptake, pseudo rate constant, Hammett basicity,

\begin{tabular}{|c|c|c|c|c|c|}
\hline DESs & $k\left(\min ^{-1}\right) \times 10^{2}$ & $\begin{array}{l}\mathrm{CO}_{2} \text { uptake } \\
(\mathrm{w} / \mathrm{w} \%)\end{array}$ & $H_{-}$ & $\alpha$ & $\beta$ \\
\hline$[\mathrm{ChCl}][\mathrm{EA}]=1: 6$ & 25.9 & 29.2 & 4.83 & 0.64 & 0.68 \\
\hline$[\mathrm{ChCl}][\mathrm{DEA}]=1: 12$ & 14.9 & 19.6 & 4.40 & 0.78 & 0.68 \\
\hline$[\mathrm{ChCl}][\mathrm{TEA}]=1: 3$ & 5.0 & 8.0 & 4.37 & 0.81 & 0.68 \\
\hline$[\mathrm{TBAB}][\mathrm{EA}]=1: 5$ & 15.0 & 19.7 & 4.54 & 0.42 & 0.81 \\
\hline$[\mathrm{TBAB}][\mathrm{DEA}]=1: 2$ & 4.1 & 9.6 & 4.43 & 0.45 & 0.78 \\
\hline$[\mathrm{TBAB}][\mathrm{TEA}]=1: 2$ & 3.1 & 2.5 & 4.35 & 0.53 & 0.76 \\
\hline$[$ DETA.Cl $][$ EDA $]=1: 4$ & 15.7 & 32.2 & 6.51 & 0.83 & 0.65 \\
\hline$[$ DETA.Cl] $][\mathrm{AP}]=1: 4$ & 12.4 & 18.3 & 4.43 & 1.03 & 0.61 \\
\hline [DETA.Cl][TEPA] $=1: 4$ & 2.9 & 9.9 & 5.59 & 0.57 & 1.28 \\
\hline
\end{tabular}
Kamlet-Taft parameters and viscosity in different DESs

Errors associated with the pseudo rate constant $(k)$, wt $\% \mathrm{CO}_{2}$, polarity parameters and Hammett basicity are $\pm 0.003, \pm 0.004, \pm 0.004$, and, \pm 0.003 , respectively.
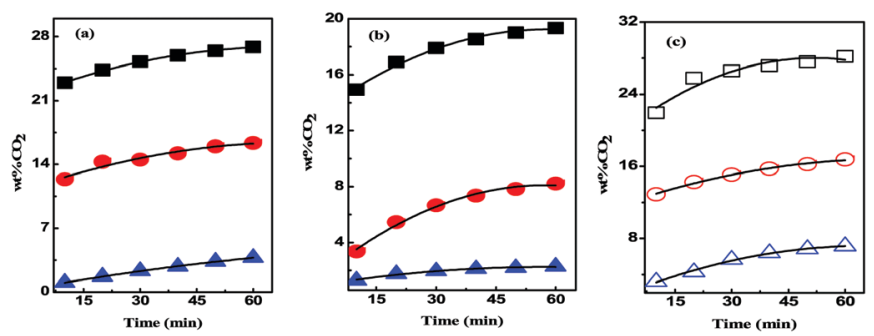

Fig. $2 \mathrm{CO}_{2}$ uptake in (a) [ChCl]- and (b) [TBAB]-based DESs containing HBDs [EA] ( $\mathbf{\square}),[D E A](\circlearrowleft)$ and [TEA] $(\boldsymbol{\Delta})$ whereas (c) in [DETA.Cl]-class of DESs comprising [EDA] $(\square),[$ AP] $(O)$ and $[T E P A](\triangle)$ as HBDs.

but affords an idea about how slow or fast $\mathrm{CO}_{2}$ capture in different DESs is. The larger value of $k$ results in higher $\mathrm{CO}_{2}$ $\mathrm{w} / \mathrm{w} \%$. The goodness of fit of eqn (1) in different DESs is shown in the $\mathrm{ESI} \dagger$ (Table S3).

For convenience, the dependence of $\mathrm{CO}_{2}$ uptake on the structural parameters of DESs is analyzed in terms of the change in HBD and HBA components. The influence of different HBDs on the $\mathrm{CO}_{2}$ uptake incorporated with similar HBAs is demonstrated in Fig. 2.

In [ChCl]- and [TBAB]-classes of DESs, $\mathrm{CO}_{2}$ wt $\%$ lowers with the decreasing basicity of HBD from [EA] to [DEA] to [TEA] as shown in Fig. 2(a) and (b). The large difference in the $\mathrm{CO}_{2}$ absorption isotherms in [ChCl]- and [TBAB]-based DESs indicates the influence of $\mathrm{HBDs}$ on $\mathrm{CO}_{2}$ capture. Furthermore, the Hammett basicity $(k)$ of DESs and aqueous basicity $\left(\mathrm{p} K_{\mathrm{a}}\right)$ of $\mathrm{HBD}$ components were noted as guiding factors in $\mathrm{CO}_{2}$ loading $(\mathrm{w} / \mathrm{w} \%)$ in $[\mathrm{ChCl}]$ - and [TBAB]-based DESs.

$$
\begin{gathered}
{[\mathrm{ChCl}][\mathrm{EA}](4.83)>[\mathrm{ChCl}][\mathrm{DEA}](4.40)>[\mathrm{ChCl}][\mathrm{TEA}](4.37) .} \\
{[\mathrm{EA}](9.45)>[\mathrm{DEA}](8.88)>[\mathrm{TEA}](7.77) .}
\end{gathered}
$$

The above ordering of DESs in terms of $H_{-}$and $\mathrm{p} K_{\mathrm{a}}$ though justifies the role of basicity in $\mathrm{CO}_{2} \mathrm{w} / \mathrm{w} \%$ in [ChCl]- and [TBAB]based DESs; but, the decrease in the $\mathrm{CO}_{2} \mathrm{w} / \mathrm{w} \%$ to $1 / 4$ th and $1 / 8$ th upon moving from [EA] to [TEA] in [ChCl]- and [TBAB]classes of DESs despite a small change in the $H_{-}$and $\mathrm{p} K_{\mathrm{a}}$ values 
suggests that basicity alone cannot be responsible for the sharp decrease in $\mathrm{CO}_{2} \mathrm{wt} \%$.

The above inference becomes more evident when discussing the $\mathrm{CO}_{2}$ uptake results in [DETA.Cl]-based DESs with [EDA], [AP] and [TEPA] as HBDs (Fig. 2(c)). In the [DETA.Cl]-class of DESs, the $\mathrm{CO}_{2}$ loading (w/w\%) does not follow the order of $H_{-}$or $\mathrm{p} K_{\mathrm{a}}$ as shown below.

$$
\begin{gathered}
{[\text { DETA.Cl }][\text { EDA }](6.51)>[\text { DETA.Cl }][\text { TEPA }](5.59)>} \\
{[\text { DETA.Cl }][\text { AP }](4.43) .} \\
{[\text { EDA }](10.71)>[\text { TEPA }](9.81)>[\text { AP }](4.09) .}
\end{gathered}
$$

As the above arrangements of DESs in terms of $H_{-}$or $\mathrm{p} K_{\mathrm{a}}$ do not correspond with $\mathrm{CO}_{2} \mathrm{wt} \%$, the basicity appears ineffective here. Furthermore, nearly two-fold higher $\mathrm{CO}_{2}$ uptake is noted in [DETA.Cl] $[\mathrm{AP}]=1: 4$ than in [DETA.Cl] [TEPA] $=1: 4$ despite the lower $H_{-}$or $1 / 2 \mathrm{p} K_{\mathrm{a}}$ value of the former. These observations confirm that high $\mathrm{CO}_{2}$ uptake in these DESs is controlled neither by $H_{-}$nor $\mathrm{p} K_{\mathrm{a}}$ and seems to be guided by a rather complex interaction between the HBD and HBA components.

Moreover, the HBA's comparison shows higher $\mathrm{CO}_{2}$ loading in [ChCl]- than in [TBAB]-based DESs despite the similar HBD components (Fig. 3). The large difference in the $\mathrm{CO}_{2}$ uptake capacity of $[\mathrm{ChCl}]$ and $[\mathrm{TBAB}]$ could be partially due to the steric repulsion caused by the long butyl chain present in the [TBAB] and partly to the higher molar ratio of the HBD components. A crossover point is noticed in the case of [TEA] owing to the viscosity variation during the $\mathrm{CO}_{2}$ capture (Fig. 3(c)). ${ }^{31}$ Given these observations, it can be conferred that along with the basicity of HBD components, the structural and electronic features of HBAs also play an important role in the $\mathrm{CO}_{2}$ capture.

In DESs, both the donor and acceptor lose their identity and result in a new continuum with a different set of solvation properties. Therefore, the inclusion of the solvation properties of DESs, which arises due to the complex donor-acceptor interactions, in the current discussion might help in identifying the governing factors which control the $\mathrm{CO}_{2}$ capture.

The solvation behaviors of DESs and ILs have been perceived in terms of the electronic transition energy $\left(E_{\mathrm{T}}(30)\right)$ and Kamlet-Taft parameters, which comprise of hydrogen bond donor acidity $(\alpha)$, hydrogen bond acceptor basicity $(\beta)$ and the polarity index $\left(\pi^{*}\right) .{ }^{35}$ The details about the polarity parameters are discussed in the ESI $\dagger$ (see entry 7 ).
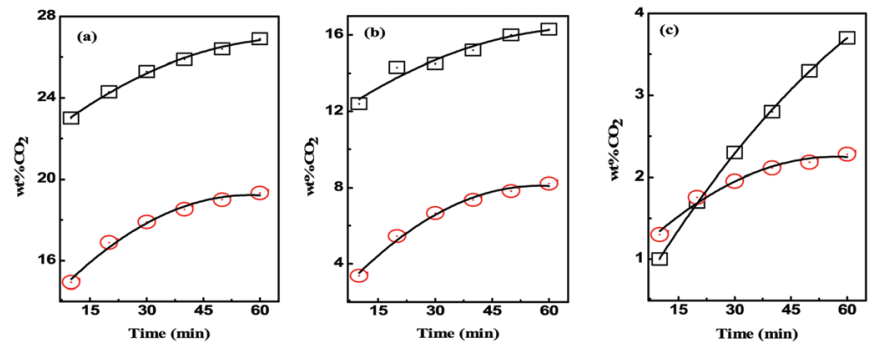

Fig. $3 \mathrm{CO}_{2}$ uptake in $[\mathrm{ChCl}-(\cdot)$ and $[\mathrm{TBAB}]-(\odot)$ based DESs containing (a) $[E A]$, (b) $[D E A]$ and (c) [TEA] as HBDs.
The Kamlet-Taft parameters $(\alpha$ and $\beta$ ) for different DESs are shown in Table 1 . The correlation of polarity parameters with the $\mathrm{CO}_{2}$ uptake data for [TBAB]-based DESs is exhibited in Fig. 4. As shown in Fig. 4(a), high $\mathrm{CO}_{2}$ uptake is favored in less polar DESs. An inverse trend between $\pi^{*}$ and $E_{\mathrm{T}}(30)$ for the [TBAB]-class of DESs is due to the high $\beta$ value (Fig. 4(a) and (c)). The $E_{\mathrm{T}}(30)$ increases upon increasing the number of ethanolic $\left(-\mathrm{CH}_{2}-\mathrm{CH}_{2}-\mathrm{OH}\right)$ moieties in the HBD component. The trend of $\mathrm{CO}_{2}$ against $\alpha$ and $\beta$ indicates that higher $\mathrm{CO}_{2}$ uptake can be achieved in DESs by complexing less acidic and strongly basic moieties (Fig. 4(b)). Contrary to [ChCl]- and [DETA.Cl]-classes of DESs, [TBAB]-based DESs possess lower $E_{\mathrm{T}}(30)$, smaller $\alpha$ but higher $\beta$. The [ChCl]-based DESs have higher $E_{\mathrm{T}}(30)$ but comparable $\alpha$ and $\beta$ values than the [TBAB]class of DESs. Though the trend of $E_{\mathrm{T}}(30), \alpha$ and $\beta$ against the $\mathrm{CO}_{2}$ uptake is similar in [ChCl]- and [TBAB]-based DESs, higher $\mathrm{CO}_{2} \mathrm{wt} \%$ is noted in [ChCl]-based DESs than in the [TBAB]-class of DESs with identical HBDs. However, none of these polarity parameters correlate with the $\mathrm{CO}_{2} \mathrm{w} / \mathrm{w} \%$ in all DESs.

A temperature-promoted $\mathrm{CO}_{2}$ capture study in ethylenediamine (EDA)-based DESs showed that rather than the hydrogen bond donor basicity $(\beta)$, comparable $\alpha$ and $\beta$ values correlate well with the $\mathrm{CO}_{2} \mathrm{w} / \mathrm{w} \%$. ${ }^{43}$ The comparable $\alpha$ and $\beta$ cause "synergism" in the DES and result in higher $\mathrm{CO}_{2} \mathrm{w} / \mathrm{w} \%$. Synergistic interaction is noted as a thermodynamically controlled phenomenon and takes place under the positive set of enthalpy $\left(\Delta H^{\circ}\right)$ and entropy $\left(\Delta S^{\circ}\right)$ changes. $^{43}$ In an ideal case, for maximum synergistic interaction $|\alpha-\beta|=0$. In a previous study, a near-zero $|\alpha-\beta| \approx 0$ is linked with the high $\mathrm{CO}_{2}$ uptake in DESs. ${ }^{43}$ The synergistic action is widely acknowledged in catalysis and polarity measurements of binary systems. ${ }^{43,44}$

Synergistic interaction was noted operative in the DESs employed for $\mathrm{CO}_{2}$ capture. [ChCl][EA] = 1:6 showed higher $\mathrm{CO}_{2}$ uptake $(29.2 \mathrm{wt} \%)$ than $[\mathrm{TBAB}][\mathrm{EA}]=1: 3(19.7 \mathrm{wt} \%)$ because of the equivalent $\alpha(0.64)$ and $\beta(0.68)$ values in the former than the latter. Likewise, $[\mathrm{ChCl}][\mathrm{DEA}]=1: 12$ has similar $\alpha$ and $\beta$ and hence possesses higher $\mathrm{CO}_{2}$ uptake (19.6 wt\%) than $[\mathrm{TBAB}][\mathrm{DEA}]=1: 2(9.6 \mathrm{wt} \%)$ for which $\beta \gg \alpha$. Analogously, higher $\mathrm{CO}_{2}$ uptake in [ChCl][TEA] $=1: 3$ in comparison with $[\mathrm{TBAB}][\mathrm{TEA}]=1: 2$ can be ascribed to the nearly lower $|\alpha-\beta|$ values.

In the [DETA.Cl]-class of DESs, the strongest synergistic interaction prevailed in [DETA.Cl] [EDA] $=1: 4$ and resulted in $32.2 \mathrm{wt} \% \mathrm{CO}_{2}$ owing to the comparable but higher $\alpha$ and $\beta$
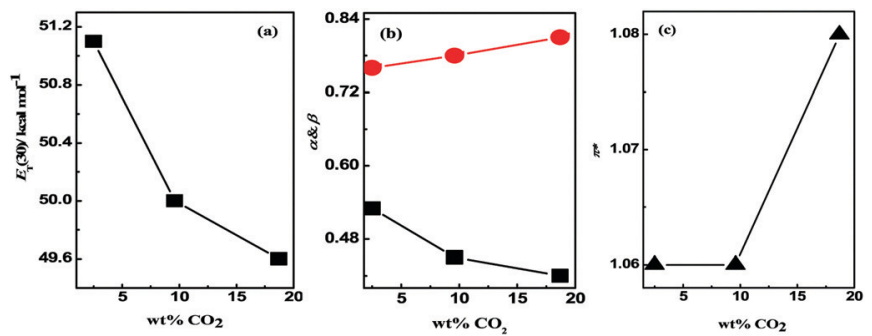

Fig. 4 A correlation between the $\mathrm{CO}_{2}$ uptake (wt\%) and (a) $E_{\mathrm{T}}(30)$, (b) $\alpha$ ( $\mathbf{\square})$ and $\beta$ (O) and (c) $\pi^{*}(\boldsymbol{\Delta})$ in [TBAB]-based DESs. 

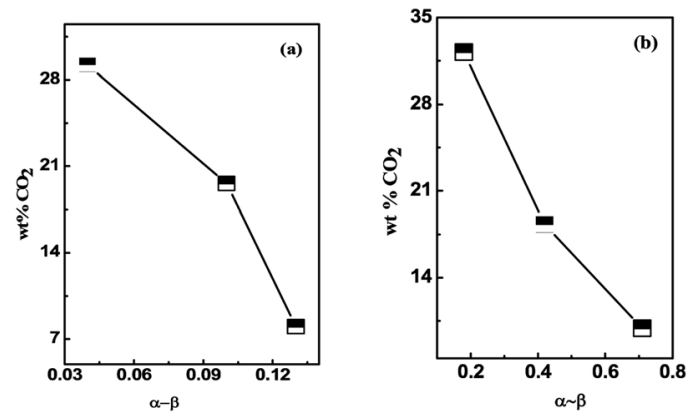

Fig. 5 A correlation between $\mathrm{CO}_{2}$ wt\% and $|\alpha-\beta|$ in (a) $[\mathrm{ChCl}-$ and (b) [DETA.Cl]-based DESs.

values. [DETA.Cl][AP] $=1: 4$ and [DETA.Cl][TEPA] $=1: 4$ have higher $|\alpha-\beta|$ and hence $18.3 \mathrm{wt} \%$ and $9.9 \mathrm{wt} \%$ of $\mathrm{CO}_{2}$ were obtained, respectively. The greater $|\alpha-\beta|$ causes an energy difference between the donor and acceptor moieties and disfavor high $\mathrm{CO}_{2}$ capture, whereas, the comparable $\alpha$ and $\beta$ values bring the donor and acceptor together for optimum $\mathrm{CO}_{2} \mathrm{w} / \mathrm{w} \%$. Fig. 5 exhibits the dependence of $\mathrm{CO}_{2} \mathrm{wt} \%$ on $|\alpha-\beta|$ in [ChCl]- and [DETA.Cl]-based DESs.

The above discussion delineates the importance of synergistic interaction in high $\mathrm{CO}_{2}$ capture in DESs. The synergistic interaction becomes important in cases where a direct correlation of basicity or acidity with the observation is not feasible. The $\mathrm{CO}_{2}$ uptake analysis in [TBAB]-, [ChCl]- and [DETA.Cl]-based DESs represents one such case, where $\mathrm{CO}_{2}$ uptake resulting in the studied DESs can be explained based on the $|\alpha-\beta|$ values.

In conclusion, we have discussed the importance of the synergistic interaction upon $\mathrm{CO}_{2}$ capture in various classes of DESs. The above investigation demonstrates that neither the high Hammett basicity $H_{-}$nor $\mathrm{p} K_{\mathrm{a}}$ results in high $\mathrm{CO}_{2}$ capture as noted in the case of [DETA.Cl][TEPA] $=1: 4\left(H_{-}=5.59\right.$ and $\beta=1.28)$. Alternatively, comparable $\alpha$ and $\beta$ values in a DES establish synergistic interactions and favour high $\mathrm{CO}_{2}$ uptake. We believe that this study will motivate researchers to explore other important factors such as multiple-site- and intermolecularinteractions which will help in developing the understanding of acidic gas capture and conversion to useful products.

This work was part of the activities of the Technical Chemistry, Department of Chemistry, Chemical-Biological Centre, Umeå University, Sweden, as well as the Johan Gadolin Process Chemistry Centre at Åbo Akademi University in Finland. The Bio4Energy programme, Kempe Foundations and Wallenberg Wood Science Center are gratefully acknowledged.

\section{Conflicts of interest}

There are no conflicts to declare.

\section{References}

1 B. Metz, O. Davidson, H. de Coninck, M. Loos and L. Meyer, Cambridge University Press, 2005, www.ipcc.ch/publication s_and_data_reports.html\#1, accessed 9.07.2010.
2 M. Bui, C. S. Adjiman, A. Bardow, E. J. Anthony, A. Boston, S. Brown, P. S. Fennell, S. Fuss, A. Galindo, L. A. Hackett, J. P. Hallett, H. J. Herzog, G. Jackson, J. Kemper, S. Krevor, G. C. Maitland, M. Matuszewski, I. S. Metcalfe, C. Petit, G. Puxty, J. Reimer, D. M. Reiner, E. S. Rubin, S. A. Scott, N. Shah, B. Smit, J. P. M. Trusler, P. Webley, J. Wilcox and N. Mac Dowell, Energy Environ. Sci., 2018, 11, 1062-1176.

3 F. Wang, J. Zhao, H. Miao, J. Zhao, H. Zhang, J. Yuan and J. Yan, Appl. Energy, 2018, 230, 734-749.

4 G. Astarita, D. W. Savage and A. Bisio, Gas treating with chemical solvents, John Wiley \& Sons, New York, 1983.

5 T. Welton, Chem. Rev., 1999, 99, 2071-2084.

6 E. L. Smith, A. P. Abbott and K. S. Ryder, Chem. Rev., 2014, 114, 11060-11082.

7 L. A. Blanchard, D. Hancu, E. J. Beckman and J. F. Brennecke, Nature, 1999, 399, 28-29.

8 K. R. Seddon, Nature, 2003, 2, 363-365.

9 Y. H. Chen, S. J. Zhang, X. L. Yuan, Y. Q. Zhang, X. P. Zhang, W. B. Dai and R. Mori, Thermochim. Acta, 2006, 441, 42-44.

10 X. L. Yuan, S. J. Zhang, J. Liu and X. M. Lu, Fluid Phase Equilib., 2007, 257, 195-200.

11 D. Wappel, G. Gronald, R. Kalb and J. Draxler, Int. J. Greenhouse Gas Control, 2010, 4, 486-494.

12 M. Hasib-ur-Rahman, M. Siaj and F. Larachi, Chem. Eng. Process., 2010, 49, 313-322.

13 E. D. Bates, R. D. Mayton, I. Ntai and J. H. Davis, J. Am. Chem. Soc., 2002, 124, 926-927.

14 B. E. Gurkan, J. C. de la Fuente, E. M. Mindrup, L. E. Ficke, B. F. Goodrich, E. A. Price, W. F. Schneider and J. F. Brennecke, J. Am. Chem. Soc., 2010, 132, 2116-2117.

15 B. F. Goodrich, J. C. de la Fuente, B. E. Gurkan, D. J. Zadigian, E. A. Price, Y. Huang and J. F. Brennecke, Ind. Eng. Chem. Res., 2011, 50, 111-118.

16 Y. Zhang, S. Zhang, X. Lu, Q. Zhou, W. Fan and X. Zhang, Chem. - Eur. J., 2009, 15, 3003-3011.

17 C. Wang, X. Luo, H. Luo, D.-E. Jiang, H. Li and S. Dai, Angew. Chem., Int. Ed., 2011, 50, 4918-4922.

18 H. Tang and C. Wu, ChemSusChem, 2013, 6, 1050-1056.

19 B. Gurkan, B. F. Goodrich, E. M. Mindrup, L. E. Ficke, M. Massel, S. Seo, T. P. Senftle, H. Wu, M. F. Glaser, J. K. Shah, E. J. Maginn, J. F. Brennecke and W. F. J. Schneider, J. Phys. Chem. Lett., 2010, 1, 3494-3499.

20 T. Oncsik, R. Vijayaraghavan and D. R. MacFarlane, Chem. Commun., 2018, 54, 2106-2109.

21 Y. Wu, Y. Zhao, R. Li, B. Yu, Y. Chen, X. Liu, C. Wu, X. Luo and Z. Liu, ACS Catal., 2017, 7, 6251-6255.

22 C. Wang, H. Luo, D. Jiang, H. Li and S. Dai, Angew. Chem., Int. Ed., 2010, 49, 5978-5981.

23 L. M. Galan Sanchez, G. W. Meindersma and A. B. de Haan, Chem. Eng. Res. Des., 2007, 85, 31-39.

24 P. J. Carvalho, K. A. Kurnia and J. A. P. Coutinho, Phys. Chem. Chem. Phys., 2016, 18, 14757-14771.

25 X. M. Liu, G. H. Zhou, S. J. Zhang and X. Q. Yao, Fluid Phase Equilib., 2009, 284, 44-49.

26 J. M. Zhang, S. J. Zhang, K. Dong, Y. Q. Zhang, Y. Q. Shen and X. M. Lv, Chem. - Eur. J., 2006, 12, 4021-4026. 
27 A. P. Abbott, G. Capper, D. L. Davies, R. K. Rasheed and V. Tambyrajah, Chem. Commun., 2001, 2010-2011.

28 A. P. Abbott, D. Boothby, G. Capper, D. L. Davies and R. K. Rasheed, J. Am. Chem. Soc., 2004, 126, 9142-9147.

29 A. Abo-Hamad, M. Hayyan, M. A. H. AlSaadi and M. A. Hashim, Chem. Eng. J., 2015, 273, 551-567.

30 B. Tang, H. Zhang and K. H. Row, J. Sep. Sci., 2015, 38, 1053-1064.

31 J. García-Álvarez, Eur. J. Inorg. Chem., 2015, 5147-5157.

32 C. Vidal, J. García-Álvarez, A. Hernán-Gómez, A. R. Kennedy and E. Hevia, Angew. Chem., Int. Ed., 2016, 55, 16145-16148.

33 Y. Zhang, X. Ji and X. Lu, Renewable Sustainable Energy Rev., 2018, 97, 436-455.

34 L. Cao, J. Huang, X. Zhang, S. Zhang, J. Gao and S. Zeng, Phys. Chem. Chem. Phys., 2015, 17, 27306-27316.

35 T. J. Trivedi, J. H. Lee, H. J. Lee, Y. K. Jeong and J. W. Choi, Green Chem., 2016, 18, 2834-2842.

36 K. Zhang, Y. Hou, Y. Wang, K. Wang, S. Ren and W. Wu, Energy Fuels, 2018, 32, 7727-7733.
37 P. J. Carvalho and J. A. P. Coutinho, Energy Environ. Sci., 2011, 4, 4614-4619.

38 G. Cui, M. Lva and D. Yang, Chem. Commun., 2019, 55, 1426-1429.

39 B. Jiang, J. Ma, N. Yang, Z. Huang, N. Zhang, X. Tantai, Y. Sun and L. Zhang, Energy Fuels, 2019, 33(8), 7569-7577.

40 S. Zeng, X. Zhang, L. Bai, X. Zhang, H. Wang, J. Wang, D. Bao, M. Li, X. Liu and S. Zhang, Chem. Rev., 2017, 117(14), 9625-9673.

41 F.-F. Chen, K. Huang, Y. Zhou, Z.-Q. Tian, X. Zhu, D.-J. Tao, D.-E. Jiang and S. Dai, Angew. Chem., Int. Ed., 2016, 55, 7166-7170.

42 S. K. Shukla and J.-P. Mikkola, Phys. Chem. Chem. Phys., 2018, 20, 24591-24601.

43 S. K. Shukla and J.-P. Mikkola, Chem. Commun., 2019, 55, 3939-3942.

44 L. Hongliang, W. Liangbing, D. Yizhou, P. Zhengtian, L. Zhuhan, C. Yawei, W. Menglin, Z. Xusheng, Z. Junfa, Z. Wenhua, S. Rui, M. Chao and Z. Jie, Nat. Nanotechnol., 2018, 13, 11-417. 